\title{
DETERMINING THE WORKING CONDITIONS OF HEAT PUMP COMPONENTS ACCORDING TO RUNNING MODES
}

\author{
Uğur Çakır ${ }^{1}$ and Kemal Çomakıı \\ ${ }^{1 *}$ Engineering Faculty, Mechanical Engineering Department, Bayburt University \\ Bayburt / TÜRKIYY \\ Phone: +904582111153; Fax +904582111172 \\ Email: ucakir@bayburt.edu.tr \\ ${ }^{2}$ Engineering Faculty, Mechanical Engineering Department, Atatürk University \\ Erzurum / TÜRKIYYE \\ Email:kcomakli@atauni.edu.tr
}

\begin{abstract}
In this study a detailed exergetic analysis is made of the components of heat pumps by changing the heat source and heat sink fluid as either water or air. To realize this aim a multifunctional heat pump test system was used, which can be run in four modes, air to air, air to water, water to air and water to water, using one compressor. When the system is run in water to air mode compressor exergy efficiency reaches its highest value. When the system is run in air to water mode the exergy efficiency of the compressor falls to its lowest value. In the heat pump's water to air mode the exergy destruction rate of the compressor becomes minimal. Exergetic performance of the condenser is best when the system is run in water to air mode. When the system runs in air to air mode, the exergy destruction rate of the condenser is at maximum, and falls to minimum when the system runs in air to water mode. Water to water is the running mode in which evaporator exergy efficiency is the best. Exergy efficiency of the evaporator decreases when the temperature of the evaporator fluid increases. Maximum compressor exergy efficiency increases according to an increase of mass flow rate is seemed in the air to air mode. The heat pump mode in which the exergy destruction rate of the compressor is minimal, is water to air mode. The running modes in which the condenser and compressor work with maximum and minimum efficiency are the same: water to air, and air to water modes. The compressor is the component which has maximum exergy efficiency with an average of $61.04 \%$ for all tests. Exergy efficiency of the condenser is lowest for all tests with an average of $14.25 \%$
\end{abstract}

Keywords: Heat pump; heat pump components; energy; exergy.

\section{INTRODUCTION}

Heat pump systems have rapidly become common all over the world due to their high efficiency and environmental friendliness. Heat pumps generally consist of four main components; compressor, expanding valve and two heat exchangers - condenser and evaporator. The components that determine the type of heat pump are the condenser and evaporator due to the type of heat source and heat sink used; the properties and thermal specifications of every component are very important for the thermal behavior of the system. The physical and thermal properties of the fluid used as heat source or sink influence the performance of components and simultaneously affect the performance of the heat pump. Commonly used heat sources and heat sinks include 
ambient air, exhaust air, lake water, river water, ground water, earth, rock, wastewater and effluent. The most common heat sources and heat sinks in heat pump systems around the world are ambient air and water (Çomaklı, UğurÇakır, Şahin, \& Kuş, 2013). Ambient air is a widely available and a free heat source for heat pumps, however, the thermodynamic performance of air source heat pump systems decreases depending on the decreasing temperature of air in the hot season and increasing temperature of air in the cool season. The heat transfer properties of water mean that water source heat pump systems offer some performance advantages over heat pump systems which use air as the heat source.

Heat pump systems are available in an array of types and combinations that can suit almost any application. For heating purposes, they can be divided into basic types, determined by the source and the destination of the heat, and the medium that the heat pump uses to either absorb or reject the heat in each of these locations. The heat transfer media at either of the heat exchangers can be either liquid (water, or often a glycol mixture) or air; sometimes it is a combination of the two. In describing the type of heat pump, the heat source is generally provided first, followed by the destination or heat sink. The main variants in common use are; air to air, water to water, water to air, air to water, ground to water, ground to air types.

Many studies and investigations have reported in the open literature on different types of heat pumps and on comparisons performed experimentally or by simulations, according to their heat sources, heat sinks, and the place they are being used, the refrigerant used as working fluid, structures and capacities of components. De Swardt and Meyer (2002), for example, reported that the performance of a reversible groundsource heat pump coupled to a municipality water reticulation system was compared experimentally and with simulations to a conventional air-source heat pump for space cooling and heating. The experimental and simulated comparisons of the ground source system to the air source system were conducted in both the cooling and heating cycles. The results showed that the utilization of a municipality water reticulation system as heat source/sink is a viable method of optimizing energy use in the air conditioning industry, especially when used in heating mode. Particularly at low ambient air temperatures, ground-source heat pumps have significant capacity $(24 \%)$ and efficiency improvement $(20 \%)$ over air-source heat pumps. Petit and Meyer (1997) made a comparison of the economic viability in South Africa of horizontal-ground source systems and air-source systems. In order to realize this aim, monthly heating and cooling capacities and coefficients of performance for both systems were determined. The payback period, net present value, and internal rate of return of the systems were calculated. It was concluded that ground source systems are more viable than air source systems.

Urchueguía et al. (2008) made an experimental comparison between a ground coupled heat pump system and a conventional air to water heat pump system, focusing on heating and cooling energy performance. The results obtained for a whole climatic season showed that the geothermal system saves, in terms of primary energy consumption, $43 \pm 17 \%$ of the energy consumed by the conventional system when the system is working in heating mode, and $37 \pm 18 \%$ when the system is working in cooling mode. The results also demonstrated that a ground source heat pump system is a viable and energy efficient alternative to conventional systems for heating and cooling applications in South European regions. Akpinar and Hepbasli (2007) reported on a comparative study of the exergetic assessment of two ground-source (geothermal) heat pump systems for residential applications. The study dealt with an exergetic 
performance evaluation of two types of ground source heat pump systems installed in Turkey, based on the actual operational data. The first one was a ground source heat pump system designed and constructed for investigating geothermal resources with low temperatures, and the second was a ground source heat pump with a vertical ground heat exchanger. Esen, Inalli, and Esen (2007) made a techno-economic comparison between a ground-couple heat pump system (GCHP) and air coupled heat pump (ACHP) system. The experimental results were obtained from June to September, the cool season, in 2004. The test results indicated that system parameters can have an important effect on performance and that GCHP systems are economically preferable to ACHP systems for the purpose of space cooling. Another paper presented an untreated sewage source heat pump (USSHP) system in which equipment for automatically avoiding clogging was used to continuously capture suspended solids in the sewage. The blockage problems caused by filtration and fouling in the heat exchanger tubes could be efficiently resolved in this system.

In an actual engineering application, the characteristic parameters of a USSHP system were tested under typical operating conditions for heating status. Based on the test results, the performances of the USSHP system were examined. The results indicated that the thermal resistance of the convective heat transfer and fouling on the sewage side in the sewage exchanger was $80 \%$ of its total thermal resistance (Liu, Ma, $\&$ Zhang, 2014). It aimed to evaluate the most suitable GSHP system configurations in case of high humidity soils and yearly balanced heat transfer on the ground side in a study. This analysis took advantage of a case study sited in Venice and consisting of the restoration of a historical building. In this analysis the GSHP system performance was calculated both in heating and in cooling conditions via detailed simulation software developed by the authors and aimed at modeling the heat pump and the borehole heat exchanger (Schibuola, Tambani, Zarrella, \& Scarpa, 2013). The performance of a cascade heat pump water heating system was investigated with a quasi-steady state analysis to discover the transient behavior of the system. The water-heating system consisted of the cascade heat pump water heater, which used R134a and R410A as refrigerants, and a water storage tank. The steady-state cascade heat pump model was developed based on experimental results and the dynamic storage tank model was created using thermodynamic equations. The model computes the several major parameters related to system performance, such as heating capacity, power consumption, coefficient of performance (Fontanesi, 2013), and the temperature distribution in a storage tank. The performance of the system was calculated for various conditions to determine the influence of ambient temperature and hot water demand (Park, Ho, \& Kim, 2013). Waheed, Oni, Adejuyigbe, Adewumi, and Fadare (2014) made a study in which enhanced VRHP models were developed to reduce heat loss and heat pump size. The strategies adopted relied on reducing the heat differential across the heat pump by utilizing external and utility streams, and processing the streams within the system. The thermo-economic and environmental performances of the developed models were compared with the base case VRHP and the conventional distillation process. The results showed that the developed models yielded considerable energy savings. Considering the present trend for short process modification payback time, the use of an external process stream is recommended to boost plant performance (Waheed et al., 2014).

In this study, an experimental multifunctional heat pump setup was designed to make a comprehensive exergetic investigation of the components (condenser, evaporator, and compressor) of four different heat pump types. The heat pumps had 
same heating capacity and same specifications. In order to achieve this aim, a multifunctional heat pump experimental setup, which could be operated in four different modes, including air to air, air to water, water to air and water to water modes, was installed in the laboratories of Mechanical Engineering Department of Atatürk University in Erzurum, Turkey. The experimental system consisted of two condensers and two evaporators, including one water-cooled and one air-cooled, two expansion valves and one compressor. The direction of refrigerant fluid used in the system could be easily changed between the condensers and evaporators with the help of valves. In this way the designed heat pump experimental setup could be operated in different modes. The study described in this paper focuses on the thermodynamic behavior of heat pump components according to the running modes. The work is carried out for four heat pump types: air to air, air to water, water to water and water to air. The individual performance of every part of the system is important for the whole system's performance. For that reason it is important to make a detailed analysis of every component of the system.

\section{EXPERIMENTAL SET UP}

Figure 1a and Figure $1 \mathrm{~b}$ shows the schematic diagram of the experimental apparatus. The system was originally designed to operate with R22. The main components of the system are a scroll compressor, an air cooled evaporator, an air cooled condenser, a water cooled condenser, thermostatic expansion valve, and other elements such as measurement and control equipment. Electrical air and water heaters are also used in order to keep the temperature of air and water passing into the evaporator and condensers at the desired levels. Two electrical fans are used to circulate the air on the evaporator and condenser which is air cooled.

First, the system was charged with 15 Bar R22 while all the valves were in opened position at the temperature of the outdoor air, and then the system was run in in the required heat pump mode by closing the relevant valves. When the running mode had to be changed, all of the valves were opened for a day to obtain equal spreading of refrigerant in the system for every mode. Temperature and pressure values in the keypoint of the plant, as shown in Figure 1a, were continuously monitored in order to check the achievement of steady state conditions. An hour was usually required to initiate start-up. After each experimental run, the raw data, which consisted of temperatures from the thermocouples, pressures from the manometers, air flow rates from the anemometer, refrigerant flow rate from the flow meters, water flow rates from the rotameters, compressor input current and voltage from the ampermeter, were recorded. The tests were performed under laboratory conditions, with air temperature at approximately $20-22^{\circ} \mathrm{C}$, and relative humidity of approximately $40 \%-60 \%$. The tests were conducted in the following order for four running mode: (i) air to air mode, (ii) air to water mode. Each experiment was repeated at least three times under the same conditions at different times. When all tests had been conducted and completed for each running mode, the experimental setup was closed and left for two days with all valves open before starting the tests for another running mode. The temperature degree and flow rate of the condenser fluid were first fixed to the constant values; $20^{\circ} \mathrm{C}-1.2 \mathrm{~kg} / \mathrm{s}$ for air, $20^{\circ} \mathrm{C}-0.15 \mathrm{~kg} / \mathrm{s}$ for water. The experiments were then performed at five different temperature levels for five different flow rate values of evaporator fluid. In the first example, the flow rate of the evaporator air adjusted to a constant value, the tests were performed for five different evaporator fluid temperatures and then the same procedure 
was applied for other experiments. The numerical values of the evaporator air temperatures and flow rates for two heat pump tests are presented in Table 1. All the measured values, which consisted of temperatures from the thermocouples, pressures from the manometers, compressor input power from the wattmeter, and flow rates of the fluids used in the system from the flow meters, rotameters and anemometers, were used to determine the thermodynamic performances of two heat pump modes.

Table 1. Levels of parameters.

\begin{tabular}{cccccccc}
\hline Parameter & Fluid & Level 1 & Level 2 & Level 3 & Level 4 & Level 5 & Level 6 \\
\hline Mass flow rate & Air & 0.41 & 0.71 & 0.83 & 1.1 & 1.2 & -- \\
$(\mathrm{kg} / \mathrm{s})$ & Water & 0.100 & 0.110 & 0.125 & 0.139 & 0.150 & -- \\
$\begin{array}{c}\text { Temperature } \\
\left({ }^{0} \mathrm{C}\right)\end{array}$ & $\begin{array}{c}\text { Evap. } \\
\text { Air }\end{array}$ & 20 & 22 & 26 & 28 & 30 & 32 \\
\hline
\end{tabular}

\section{ENERGY AND EXERGYCALCULATIONS}

An energy analysis is needed to make a comprehensive exergy analysis. Mass and energy balances are employed to determine the heat input, and energy efficiencies. From the measured parameters the heat delivered by the condenser to the air or water is calculated by;

$$
\begin{aligned}
& Q_{\text {cond-air }}=m C_{a}\left(T_{a-o u t}-T_{a-\text { in }}\right) \\
& Q_{\text {cond-w }}=m C_{w}\left(T_{w-\text { out }}-T_{w-\text { in }}\right)
\end{aligned}
$$

The heat extracted by the evaporator from the air is calculated by;

$$
\begin{aligned}
& Q_{\text {evap-a }}=m C_{a}\left(T_{a-\text { in }}-T_{a-\text { out }}\right) \\
& Q_{\text {evap-w }}=m C_{w}\left(T_{w \text {-in }}-T_{a-\text { out }}\right)
\end{aligned}
$$

The power input to the compressor is calculated by;

$$
W_{\text {compelec }}=\sqrt{3} \operatorname{Cos}(\varnothing) . U . I . W
$$

where $U$, I and $\operatorname{Cos}(\theta)$ are voltage (V), current (A) and power factor, respectively. The total exergy of a fluid, and specific exergy of water, refrigerant and air are calculated as seen below (Dinçer \& Rosen, 2007);

$$
\begin{gathered}
\dot{E x}=\dot{m} \cdot e x \\
\mathrm{ex}_{\text {air }}=\left(\mathrm{C}_{\mathrm{a}}+\omega \mathrm{C}_{\text {vapor }}\right) \mathrm{T}_{0}\left[\left(\mathrm{~T} / \mathrm{T}_{0}\right)-1-\ln \left(\mathrm{T} / \mathrm{T}_{0}\right)\right]+(1+1.6078 \omega) \mathrm{R}_{\text {air }} \mathrm{T}_{0} \ln \left(\mathrm{P} / \mathrm{P}_{0}\right) \pi \\
+\mathrm{R}_{\text {air }} \mathrm{T}_{0}\left\{(1+1.6078 \omega) \ln \left[\left(1+1.6078 \omega_{0}\right) /(1+1.6078 \omega)\right]+1.6078 \omega \ln \left(\omega / \omega_{0}\right)\right\} \\
e x_{w}=\left(h_{w}-h_{w, o}\right)-T_{o}\left(s_{w}-s_{w, o}\right) \\
e x_{r}=\left(h_{r}-h_{r, o}\right)-T_{o}\left(s_{r}-s_{r, o}\right)
\end{gathered}
$$


Determining the working conditions of heat pump components according to running modes

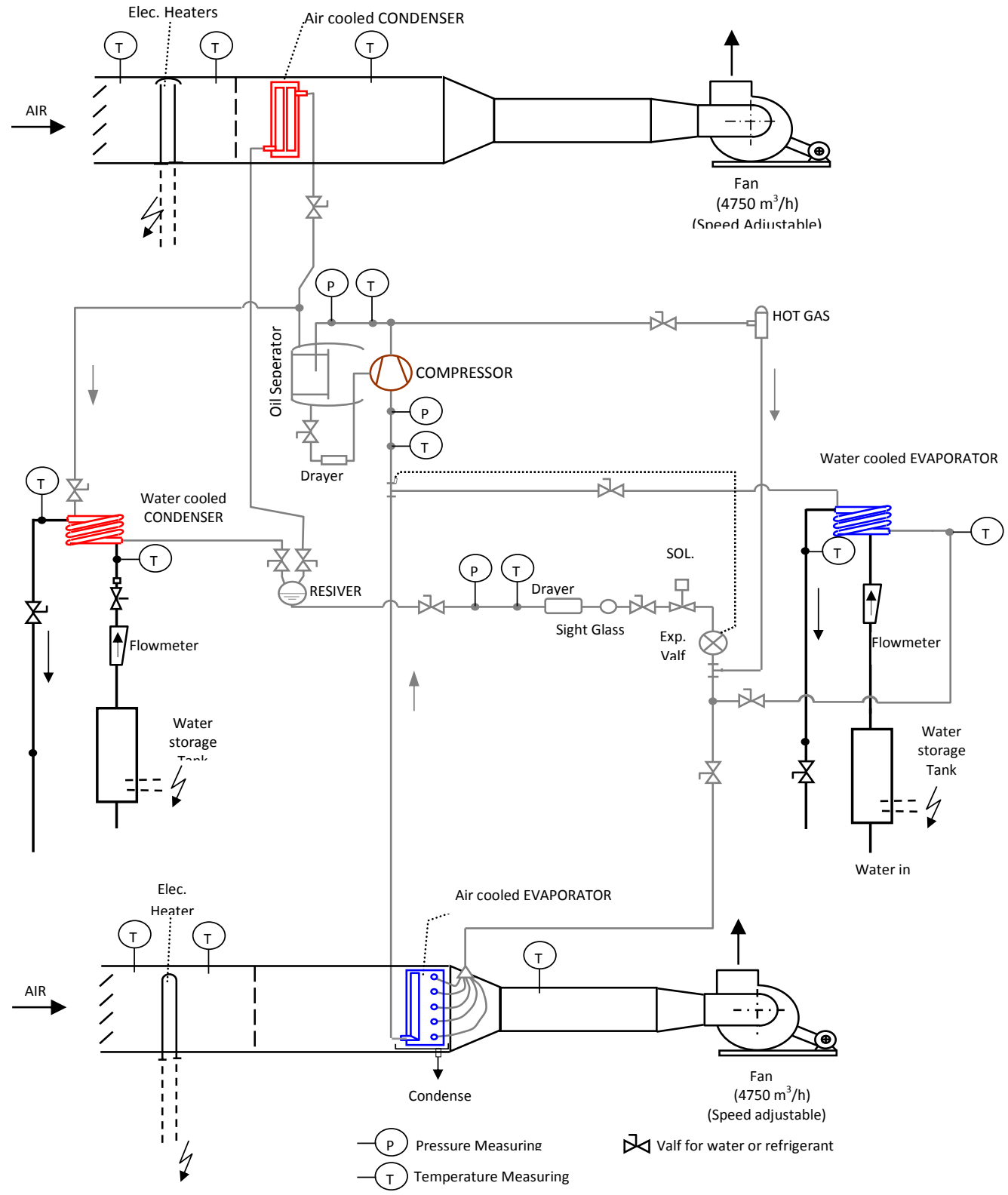

Figure 1a. Experimental system
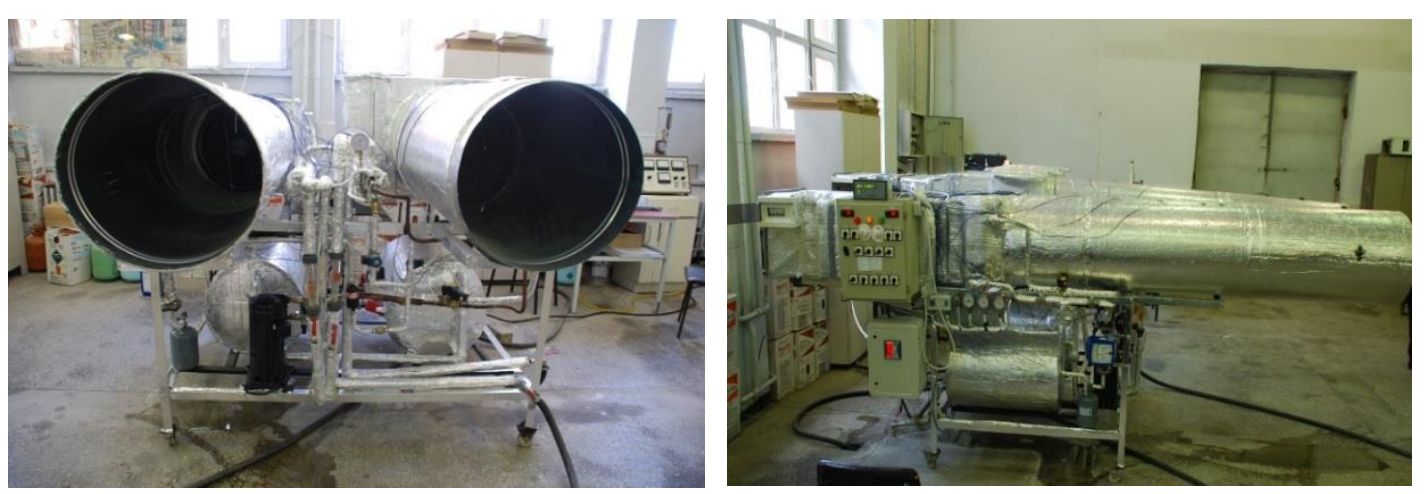

Figure 1b. View of the experimental setup 
The exergy efficiency of the components can be calculated as follows:

$$
\eta_{\text {ex.comp }}=\frac{\dot{E} x_{\text {r.in }}-\dot{E} x_{\text {r.out }}}{\dot{W}_{\text {comp elec }}}
$$

For water cooled condenser: $\quad \eta_{\text {ex.cond }}=\frac{m_{w}\left(e x_{w . i n}-e x_{w . o u t}\right)}{m_{r}\left(e x_{r . i n}-e x_{r . o u t}\right)}$

For air cooled condenser: $\quad \eta_{\text {ex.cond }}=\frac{\dot{m}_{\text {air }}\left(e x_{\text {air.in }}-e x_{\text {air.out }}\right)}{\dot{m}_{r}\left(e x_{r . i^{-}}-e x_{\text {r.out }}\right)}$

For water cooled evaporator: $\eta_{\text {ex.cond }}=\frac{m_{r}\left(e x_{r . i n}-e x_{r . o u t}\right)}{m_{w}\left(e x_{w . i n}-e x_{w . o u t}\right)}$

For air cooled evaporator: $\quad \eta_{\text {ex.cond }}=\frac{\dot{m}_{r}\left(e x_{r . i n}-e x_{\text {r.out }}\right)}{\dot{m}_{\text {air }}\left(e x_{\text {air.in }}-e x_{\text {air.out }}\right)}$

The exergy destruction rate of the compressor, condenser and evaporator can be calculated as seen below:

$$
\dot{E} x_{\text {dest comp }}=\dot{m}_{r}\left(e x_{r, \text { in }}-e x_{r, \text { out }}\right)+W_{\text {comp }}
$$

Water condenser: $\dot{E} x_{\text {dest cond } w}=\dot{m}_{r}\left(e x_{r, \text { in }}-e x_{r, o u t}\right)+\dot{m}_{w}\left(e x_{w . i n}-e x_{w . o u t}\right)$

Air condenser: $\dot{E} x_{\text {dest cond } a}=\dot{m}_{r}\left(e x_{r, \text { in }}-e x_{r, \text { out }}\right)+\dot{m}_{\text {air }}\left(e x_{\text {air.in }}-e x_{\text {air.out }}\right)$

Water evaporator: $\dot{E} x_{\text {dest evap } w}=\dot{m}_{r}\left(e x_{r, \text { in }}-e x_{r, o u t}\right)+\dot{m}_{w}\left(e x_{w . i n}-e x_{w . o u t}\right)$

Air evaporator: $\dot{E} x_{\text {dest evap a }}=\left(e x_{r, \text { in }}-e x_{r, \text { out }}\right)+\dot{m}_{\text {air }}\left(\right.$ ex $\left.x_{\text {air.in }}-e x_{\text {air.out }}\right)$

\section{RESULTS AND DISCUSSION}

Figures 2 and 3 show the change in the exergy efficiency of the compressor depending on the increase in temperature and mass flow rates of evaporator fluid for four modes. As seen in Figure 2, exergy efficiency of the compressor becomes highest when the system is run in water to air mode. When the system is run in air to water mode exergy efficiency of the compressor decreases to the lowest value. The curves which were obtained to visualize the change of compressor exergy efficiency resemble each other schematically. As presented in Figure 3, the exergy efficiency of the compressor increases slightly when the mass flow rate of the evaporator air increases for three heat pump modes, but not in air to water mode. Maximum compressor exergy efficiency increases according to increase of mass flow rate in the air to air mode.

Figures 4 and 5 present the change of the exergy destruction rate in the compressor versus increasing the evaporator fluid temperature and increasing the mass flow rate of the evaporator fluid. The curves which symbolize the change of exergy destruction rates versus change of temperature and mass flow rate are not as stable as the curves shown in Figure 2 and 3. These figures (Figure 4 and 5) support the results and comments obtained from the previous figures (2 and 3). The heat pump mode in which the exergy destruction rate of the compressor is minimal is water to air mode. The condenser is the component of the system which takes the heat energy from the 
refrigerant which comes from the compressor and feeds it to the environment to be heated. According to Figures 6 and 7, the condenser reaches its best running condition exergetically when the system is run in water to air mode, as a compressor. The running modes in which the condenser and compressor have the same maximum and minimum efficiency are water to air and air to water modes.

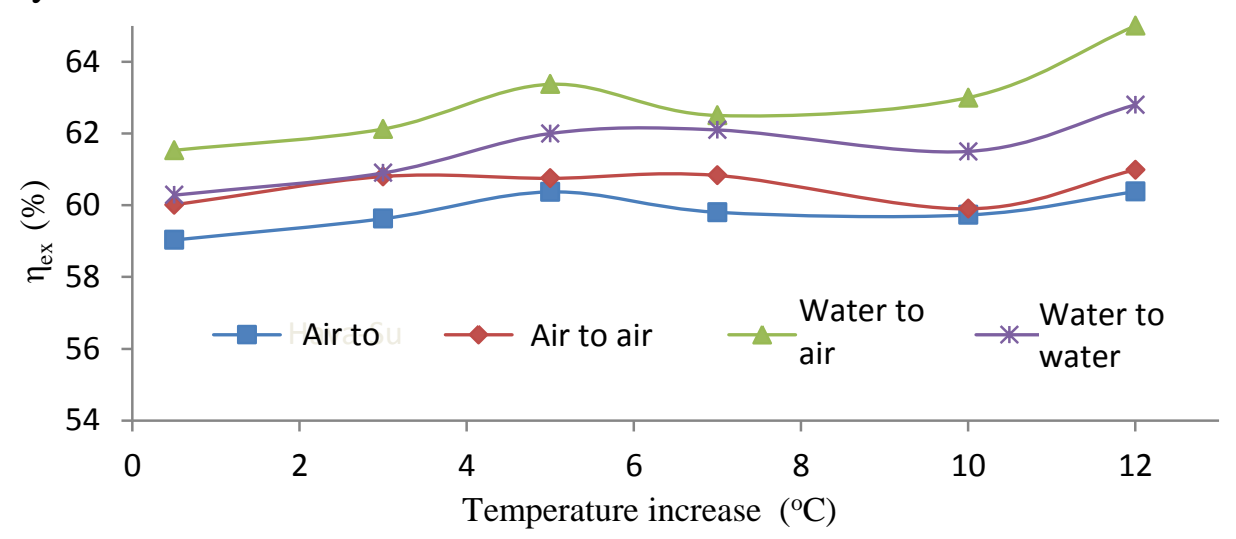

Figure 2. Change of compressor exergy efficiency versus increase of the evaporator fluid temperature

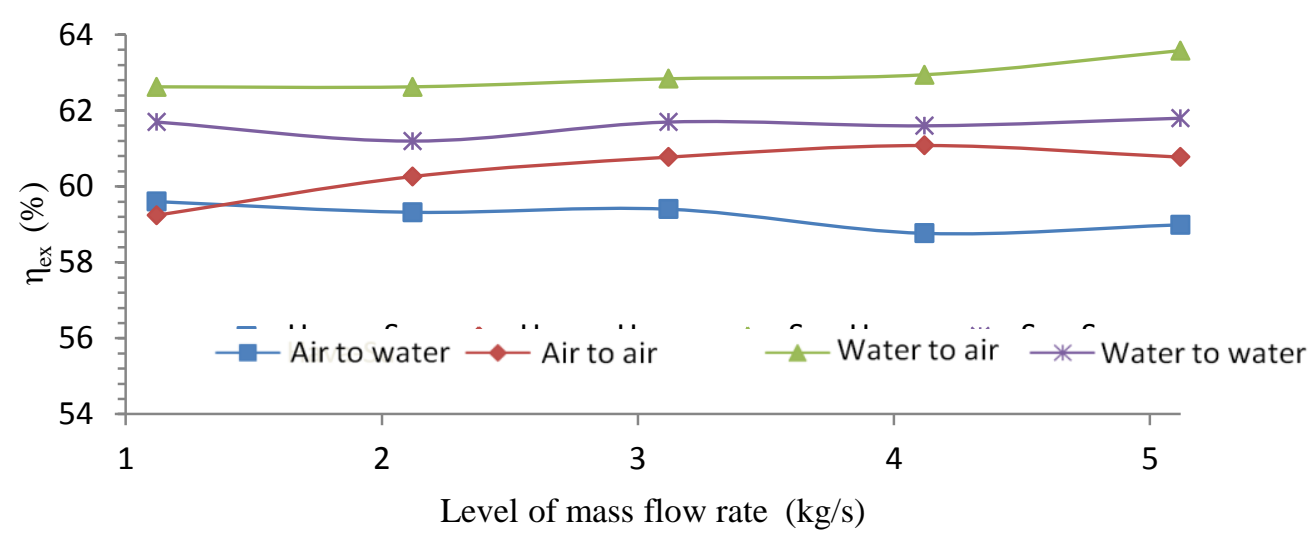

Figure 3. Change of compressor exergy efficiency versus increase of the mass flow rate of the evaporator fluid

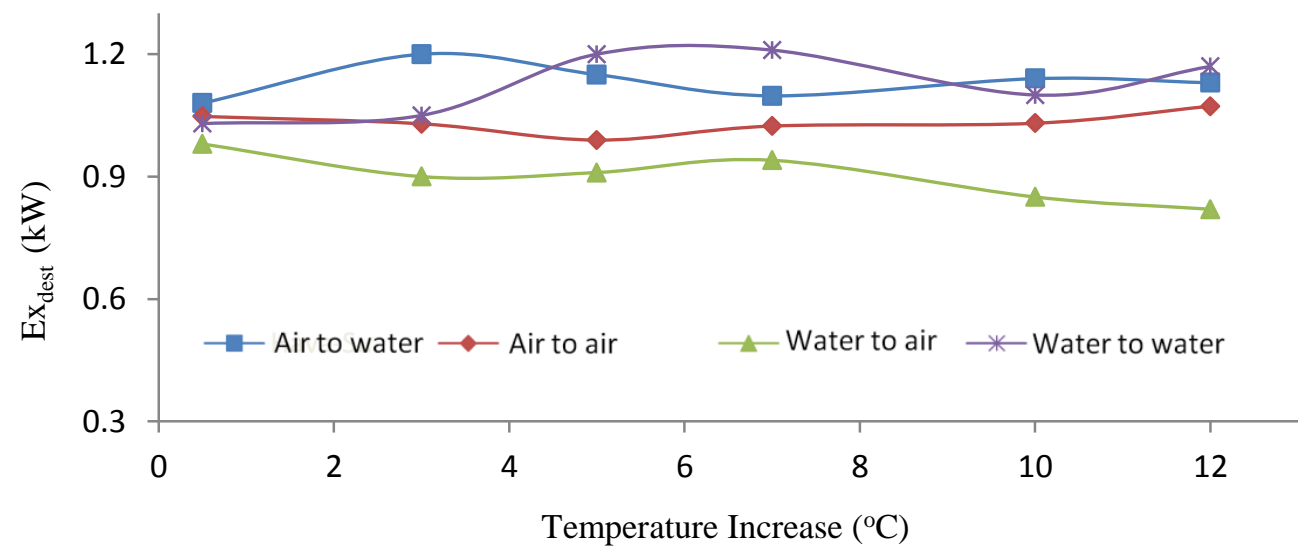

Figure 4. Change of the rate of exergy destruction in the compressor versus increase of the evaporator fluid temperature 


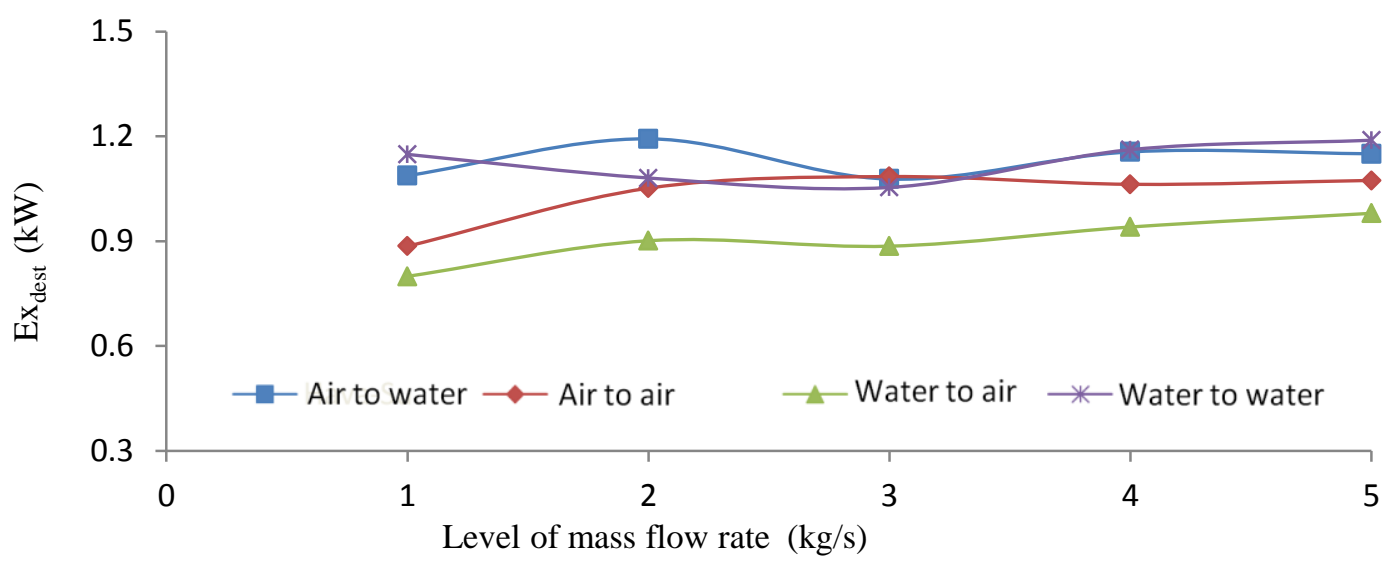

Figure 5. Change of the rate of exergy destruction in the compressor versus increase of the mass flow rate of the evaporator fluid

Figures 8 and 9 show the treatment of the condenser depending on the exergy destruction rate according to the change of temperature and mass flow rate of evaporator fluid. When the system runs in air to air mode the exergy destruction rate of the condenser reaches maximum and it falls to minimum when the system runs in air to water mode. Exergy destruction in the condenser increases with the increase in mass flow rate and the temperature of the evaporator external fluid. The results obtained from Figures 6 and 7 and Figures 8 and 9 do not support each other but that is not an abnormal situation. This situation may be explained by clarifying the meanings of exergy efficiency and exergy destruction. Exergy efficiency is explained as the ratio between the total exergy that is given to the output from the system and the total exergy that is taken from any other system or fluid. Exergy destruction can be explained as the function of the initial and final thermodynamic states of a system for all participating media.

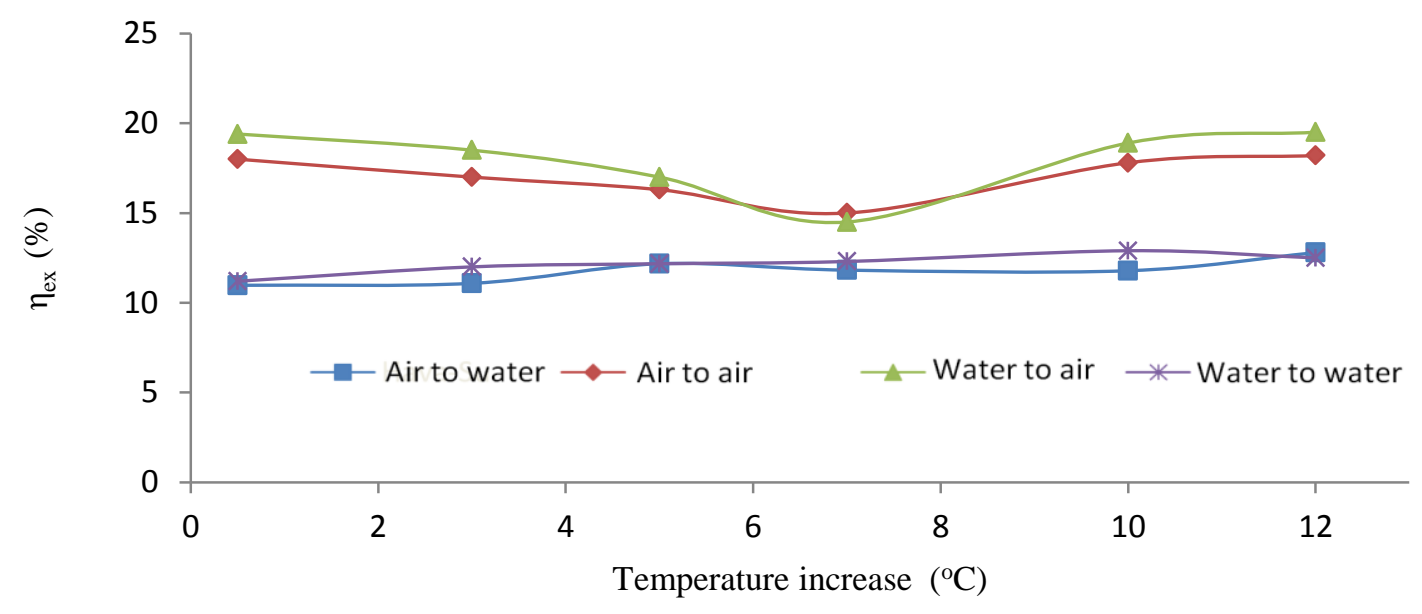

Figure 6. Change of condenser exergy efficiency versus increase of evaporator fluid temperature 
Determining the working conditions of heat pump components according to running modes

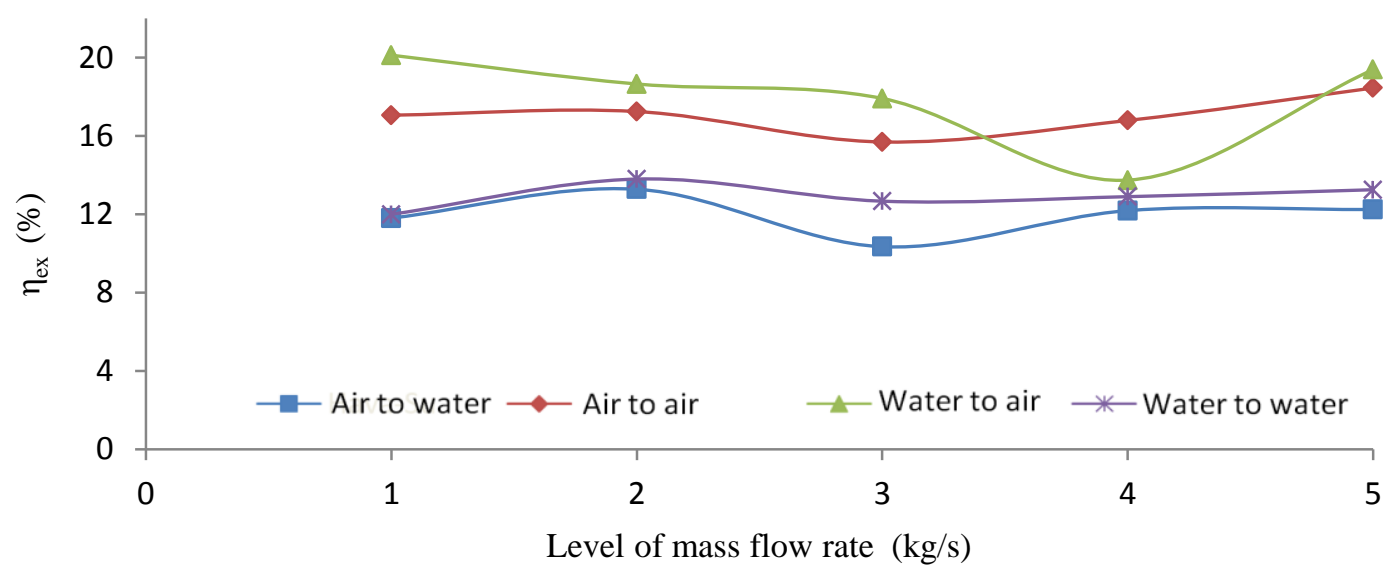

Figure 7. Change of condenser exergy efficiency versus increase of mass flow rate of the evaporator fluid

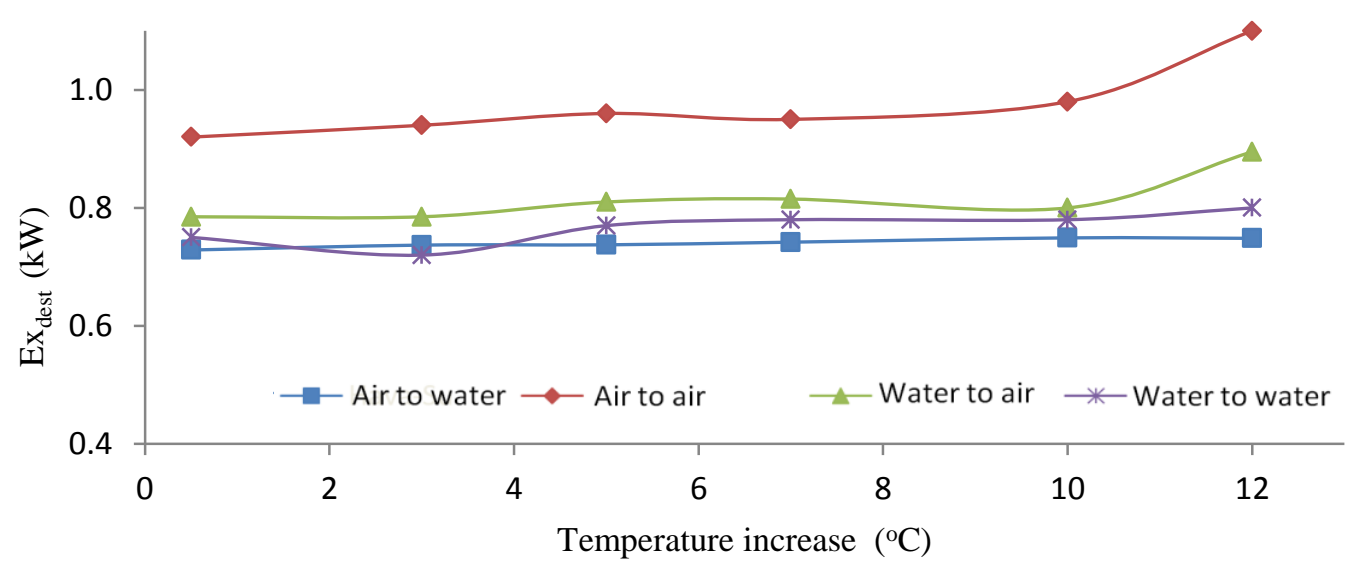

Figure 8. Change of the rate of exergy destruction in the condenser versus increase of the evaporator fluid temperature

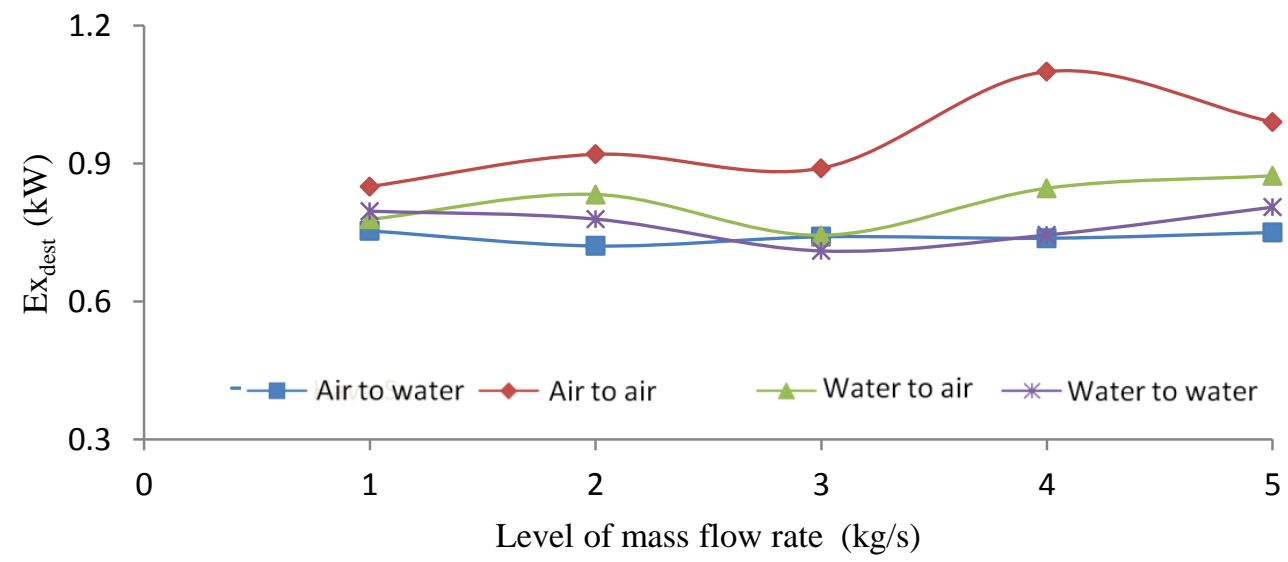

Figure 9. Change of the rate of exergy destruction in the condenser versus increase of mass flow rate of the evaporator fluid

The last component to be exergetically analyzed as in this study is the evaporator. An evaporator takes heat energy from a low temperature medium and gives 
it to the refrigerant which comes from expansion valve and moves to the compressor. Figure 10 and 11 present the change in exergy efficiency of the evaporator depending on the increase of the mass flow rate and temperature of the evaporator fluid. Maximum evaporator exergy efficiency is reached in water to water mode and the minimum is reached in air to water mode. Exergy efficiency of the evaporator decreases when the temperature of the evaporator fluid increases. An increase in the mass flow rate has a decreasing effect on the exergy efficiency of evaporator. When the system is run in air to air and air to water mode, the exergy efficiency of the evaporator decreases more than any other. This means the mass flow rate of evaporator fluid is more effective in the exergy efficiency of evaporator.

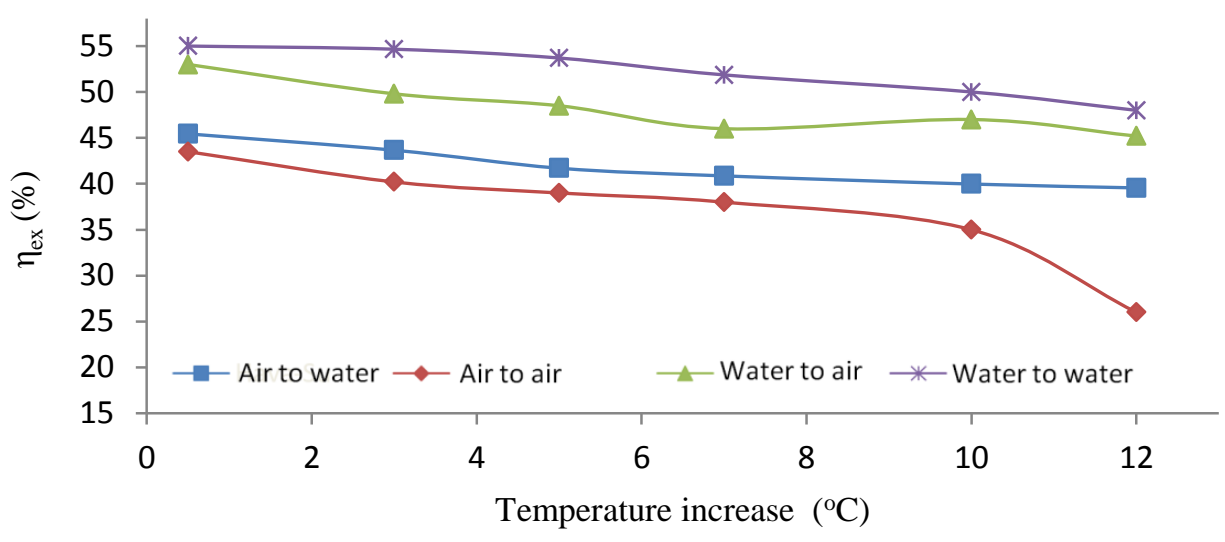

Figure 10. Change of evaporator exergy efficiency versus increaseof the evaporator fluid temperature

Figures 12 and 13 show the change of exergy destruction rate that exists in the evaporator according to temperature and the mass flow rate change of evaporator fluid. As seen in the figures, there is minimum exergy destruction in the evaporator in water to water mode and maximum exergy destruction is realized when the system is run in air to air mode. As in previous case; increasing the mass flow rate of the evaporator fluid has more effect on the exergy destruction of the evaporator than temperature increase. As a result, when mass flow rate of the evaporator fluid rises over the third level, exergy destruction of the evaporator increases more rapidly. The minimum and maximum exergy efficiency values of the components are presented in Table 2.

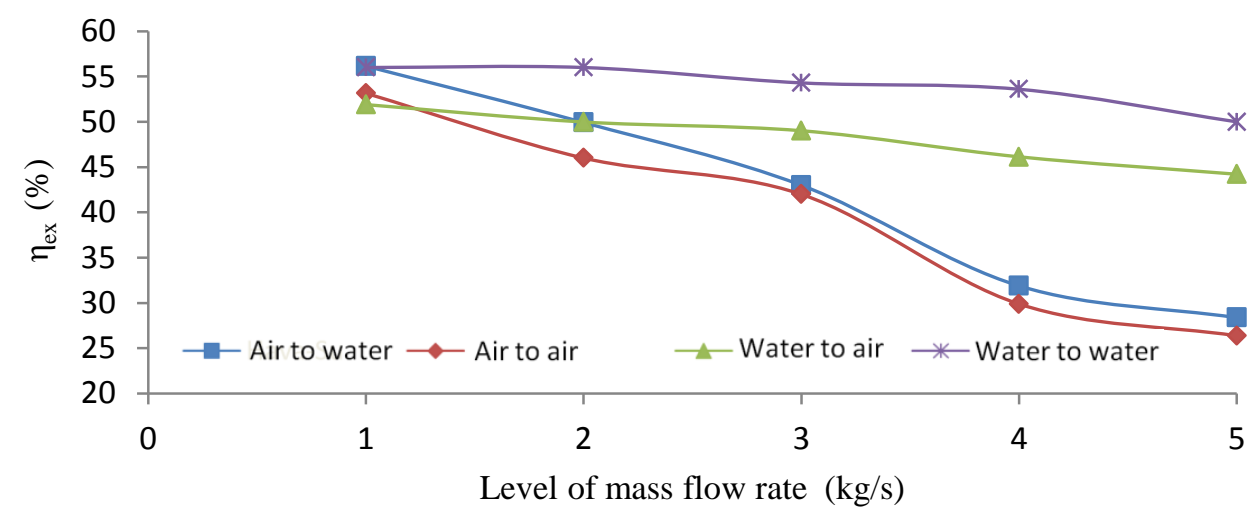

Figure 11. Change of evaporator exergy efficiency versus increase of mass flow rate of the evaporator fluid 


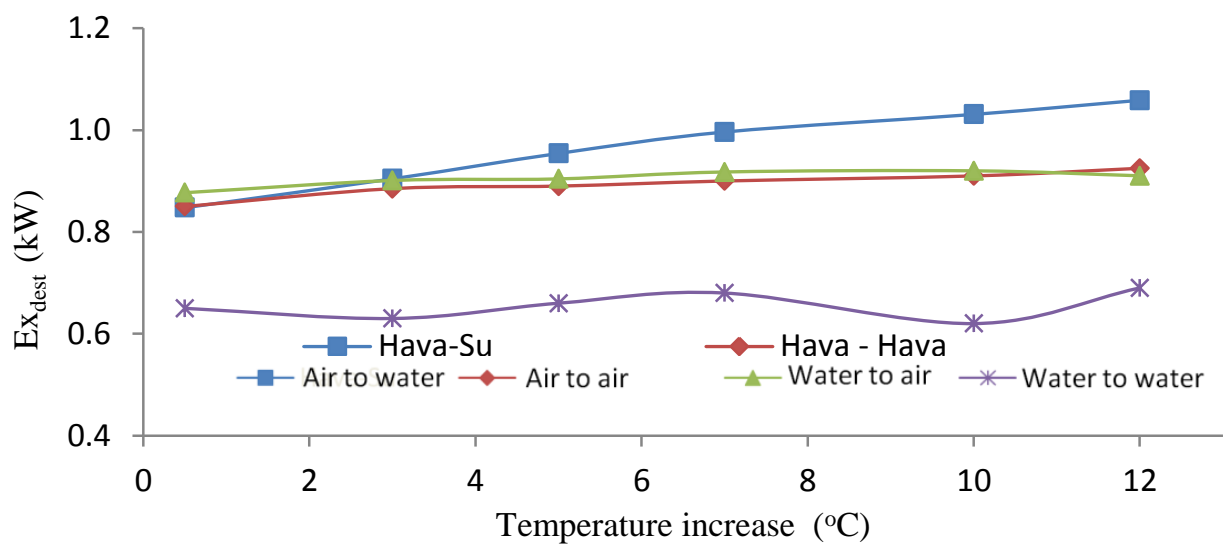

Figure 12. Change of the rate of exergy destruction in the evaporator versus increase of the evaporator fluid temperature

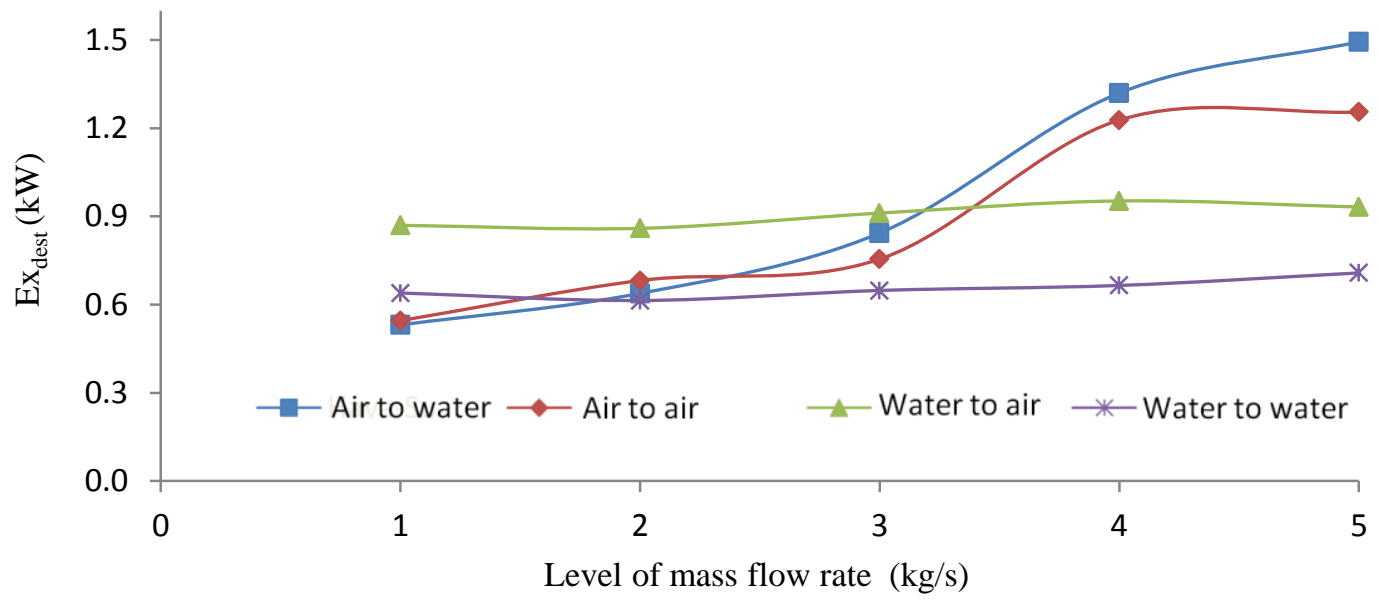

Figure 13. Change of the rate of exergy destruction in the evaporator versus increase of mass flow rate of the evaporator fluid.

Table 2. Highest and lowest values of exergy efficiency and exergy destruction rates of components.

\begin{tabular}{llcccccc}
\hline \multirow{2}{*}{ Running Mode } & & \multicolumn{3}{c}{ Compressor } & \multicolumn{2}{c}{ Condenser } & \multicolumn{2}{c}{ Evaporator } \\
\cline { 2 - 8 } & & Min. & Max. & Min. & Max. & Min. & Max. \\
\hline \multirow{2}{*}{ Air to air } & Ex. Eff. (\%) & 59.5 & 61 & 15 & 18 & 27 & 53 \\
& Ex. Dest. (kW) & 0.85 & 1.1 & 0.8 & 1.1 & 0.7 & 1.25 \\
\multirow{3}{*}{ Air to water } & Ex. Eff. (\%) & 58.5 & 60 & 10 & 13 & 28 & 45 \\
\multirow{4}{*}{ Water to air } & Ex. Dest. (kW) & 1.00 & 1.21 & 0.70 & 0.75 & 0.50 & 0.85 \\
& Ex. Eff. (\%) & 61.5 & 64.3 & 13 & 20 & 44 & 53 \\
\multirow{2}{*}{ Water to water } & Ex. Dest. (kW) & 0.8 & 0.97 & 0.70 & 0.85 & 0.80 & 0.87 \\
& Ex. Eff. (\%) & 60.5 & 63 & 11 & 14 & 48 & 56 \\
& Ex. Dest. (kW) & 1.00 & 1.20 & 0.7 & 0.8 & 0.56 & 0.72 \\
\hline
\end{tabular}




\section{CONCLUSIONS}

In this paper, an exergy analysis of the three main components of heat pumps (compressor, condenser and evaporator) has been conducted, investigating the evaporator fluid type which is used as heat source. Exergetic treatment of components primarily depends on the temperature and mass flow rates of the heat source. As in a football team, the performance of every player is very important for the total performance of the team. In heat pumps or any other thermal system, the performance of any single component of the system has a big effect on the overall system. For that reason every component of a system must be analyzed separately.

i The compressor is the component which has maximum exergy efficiency, with an average of $61.04 \%$ for all tests. This efficiency rate is not bad but it can be improved. The cooling process of a compressor can be improved, or the friction rate of the compressor subcomponents can be decreased. The use of a more beneficial oil may decrease friction.

ii An evaporator's exergy efficiency value is between that of the others but is closer to the exergy efficiency of the compressor with an average of $44.25 \%$. Some changes and improvements may be made to increase the qualification of heat transfer from external fluid to the internal fluid. This can be achieved by making adjustments to the temperature rate or velocity of the external fluid.

iii The exergy efficiency of the condenser is lowest for all tests with an average of $14.25 \%$. As a result of this very low value, the condenser is the component which needs the most attention and care to be improved.

iv Ranking of the three components according to their average exergy destruction rates from high to low is as follows: compressor at $1.2 \mathrm{~kW}$, condenser at 0.80 $\mathrm{kW}$ and evaporator at $0.78 \mathrm{~kW}$. This tells us that the condenser is the first component to improve for exergy efficiency so as to overcome the irreversibility.

\section{ACKNOWLEDGEMENTS}

This work was supported by the Scientific and Technological Research Council of Turkey (TUBITAK Project No. 105M030) and the Ataturk University Research Project Foundation (Project No. BAP-2005/16). The authors wish to thank TUBITAK and Ataturk University.

\section{REFERENCES}

Akpinar, E. K., \& Hepbasli, A. (2007). A comparative study on exergetic assessment of two ground-source (geothermal) heat pump systems for residential applications. Building and Environment, 42(5), 2004-2013.

Çomaklı, K., UğurÇakır, Şahin, E., \& Kuş, A. Ç. (2013). Energetic and exergetic comparison of air to air and air to water heat pumps according to evaporator conditions. International Journal of Automotive and Mechanical Engineering, 8, 1108-1120.

De Swardt, C., \& Meyer, J. (2002). A performance comparison between an air-source and a ground-source reversible heat pump. Paper presented at the Fuel and Energy Abstracts. 
Dinçer, I., \& Rosen, M. A. (2007). Exergy, environment and sustainable development 1st ed. Burlington: Elsevier Science.

Esen, H., Inalli, M., \& Esen, M. (2007). A techno-economic comparison of groundcoupled and air-coupled heat pump system for space cooling. Building and Environment, 42(5), 1955-1965.

Fontanesi, S., \& Giacopini, M. (2013). Multiphase cfd-cht optimization of the cooling jacket and fem analysis of the engine head of a v6 diesel engine. Applied Thermal Engineering, 52, 293-303.

Liu, Z., Ma, L., \& Zhang, J. (2014). Application of a heat pump system using untreated urban sewage as a heat source. Applied Thermal Engineering, 62(2), 747-757.

Park, H., Ho, K. D., \& Kim, M. S. (2013). Performance investigation of a cascade heat pump water heating system with a quasi-steady state analysis. Energy, 63, 283294.

Petit, P., \& Meyer, J. (1997). A techno-economic analytical comparison of the performance of air-source and horizontal-ground-source air-conditioners in south africa. International Journal of Energy Research, 21(11), 1011-1021.

Schibuola, L., Tambani, C., Zarrella, A., \& Scarpa, M. (2013). Ground source heat pump performance in case of high humidity soil and yearly balanced heat transfer. Energy Conversion and Management, 76, 956-970.

Urchueguía, J., Zacarés, M., Corberán, J., Montero, A., Martos, J., \& Witte, H. (2008). Comparison between the energy performance of a ground coupled water to water heat pump system and an air to water heat pump system for heating and cooling in typical conditions of the european mediterranean coast. Energy Conversion and Management, 49(10), 2917-2923.

Waheed, M., Oni, A., Adejuyigbe, S., Adewumi, B., \& Fadare, D. (2014). Performance enhancement of vapor recompression heat pump. Applied Energy, 114, 69-79. 